\title{
Prevalence and Risk Factors Associated with Hepatitis B and Hepatitis C Infections among Patients Undergoing Hemodialysis: A Single-Centre Study in Somalia
}

\author{
Mohamed Osman Omar Jeele $\mathbb{D}^{1},{ }^{1}$ Rukia Omar Barei Addow $\mathbb{D}^{2},{ }^{2}$ Faduma Nur Adan ${ }^{1},{ }^{1}$ \\ and Liban Hassan Jimale $\mathbb{1}^{1}$ \\ ${ }^{1}$ Mogadishu Somali Turkish Training and Research Hospital, Mogadishu, Somalia \\ ${ }^{2}$ Jazeera University Hospital, Mogadishu, Somalia \\ Correspondence should be addressed to Mohamed Osman Omar Jeele; drjeele@gmail.com
}

Received 28 July 2021; Accepted 2 November 2021; Published 13 November 2021

Academic Editor: Jaime Uribarri

Copyright (c) 2021 Mohamed Osman Omar Jeele et al. This is an open access article distributed under the Creative Commons Attribution License, which permits unrestricted use, distribution, and reproduction in any medium, provided the original work is properly cited.

\begin{abstract}
Introduction. Hemodialysis patients have the highest risk for developing hepatitis B virus (HBV) and hepatitis C virus (HCV) than the general population. There is no study available for HBV and HCV in this population in Somalia. The main objective of this study is to determine the prevalence and risk factors of HBV and HCV infections among hemodialysis patients in Somalia. Methods. A cross-sectional assessment of hemodialysis patients from January 2021 to June 2021 was used in this study. 220 patients were included in this study. Age, sex, duration of hemodialysis, number of hemodialysis sessions per week, history of blood transfusion, HbsAg, and anti-HCV antibodies were examined. Results. Out of the 220 patients, males were predominant (113 $(51.4 \%)$ ). The mean age of the participants was 52.70 . The prevalence of HBV was $7.3 \%$ (16 respondents), while the prevalence of HCV was $3.2 \%$ (7 respondents). 1 respondent (0.5\%) had both HBV and HCV. There is a positive correlation between the duration of hemodialysis and the prevalence of HBV and HCV $(r(218)=0.298, p$ value $<0.001)$, blood transfusion and prevalence of HBV and HCV $(r(218)=0.347, p$ value $<0.001)$, and the number of hemodialysis sessions per week and prevalence of HBV and HCV $(r(218)=0.402, p$ value $<0.001)$. The regression model of the combined predictors of history of blood transfusion, duration of hemodialysis, and number of dialysis sessions per week is $R^{2}=0.25$, which indicates a $25 \%$ variance in the prevalence of $\mathrm{HBV}$ and $\mathrm{HCV}$ with a significance of $F(3,216)=23.67, p<0.001$. Conclusions. The prevalence of HBV and HCV among hemodialysis patients in this study was $7.3 \%$ and $3.2 \%$, respectively. $0.5 \%$ of the respondents had both HBV and HCV. History of blood transfusion, duration of hemodialysis, and number of hemodialysis sessions per week appear to have a strong correlation with the prevalence of HBV and HCV.
\end{abstract}

\section{Introduction}

Hepatitis B virus (HBV) is a serious worldwide public health problem as 391 million people, or $5 \%$ of the world's population, had chronic hepatitis B infection as of 2017, while another 145 million cases of acute HBV infection occurred that year alone [1]. Africa has the highest regional prevalence of hepatitis B (7\%) compared to America (0.7\%) [2]. Although there is a vaccine for $\mathrm{HBV}$, it remains a global health problem. HBV infection can be acute and later become chronic, leading to end-stage liver disease and eventually to cirrhosis and hepatocellular carcinoma [3]. Hepatitis C virus (HCV) in its terms is a global burden as WHO stated in the 2017 global hepatitis report that 71 million people, approximately $1 \%$ of the global population, lived with hepatitis $\mathrm{C}$ virus [4]. HCV primarily spreads through contacting contaminated body fluids by blood-to-blood contact associated with injection drug use, poorly sterilized medical equipment, sexual contact, and needlestick injuries in healthcare [5]. It can be also transmitted by blood transfusion although it is less than one case per 2 million blood transfusions [6]. $\mathrm{HBV}$ and $\mathrm{HCV}$ are the most common 
viruses in hemodialysis population [7]. Hemodialysis patients have the highest risk for developing hepatitis $\mathrm{B}$ virus (HBV) and hepatitis $\mathrm{C}$ virus (HCV) than the general population [8]. The hemodialysis process includes removing blood from the patient with needles and plastic tubing, and then blood is pumped into the dialysis membrane. Poisons and toxins cross the dialysis membrane into the dialysate, which discards the harmful substances, and then the blood is returned to the patient [9]. The number of end-stage renal disease patients requiring hemodialysis is increasing steadily over the last decades $[10,11]$. Although renal transplantation offers improved quality of life and increases survival rate compared to hemodialysis, hemodialysis is still the choice of renal replacement therapy for end-stage renal disease patients in low-income countries such as Somalia $[12,13]$. The prevalence of chronic kidney disease in East Africa is thought to be $14.4 \%$ [14], but there is no single study that covers the prevalence of chronic kidney disease specifically in Somalia or the prevalence of hemodialysis patients in Somalia. Around the world, the prevalence of hepatitis B and hepatitis $\mathrm{C}$ viruses among hemodialysis patients varies among the countries [7]. Since there is no previous study regarding this subject made in Somalia, this study is the first of its kind to be done in Somalia and intends to be the building block of many studies to be done in Somalia over this subject. This study intends to answer if there is a relationship between the occurrence of $\mathrm{HBV}$ and $\mathrm{HCV}$ infections and hemodialysis duration or hemodialysis sessions per week or history of blood transfusions. The main objective of this study is to determine the prevalence and risk factors associated with $\mathrm{HBV}$ and $\mathrm{HCV}$ infections among hemodialysis patients.

\section{Methods}

2.1. Aim of the Study. The goal of the study is to determine the prevalence and risk factors associated with HBV and HCV infections among hemodialysis patients in Somalia.

2.2. Study Population and Design. This study is a crosssectional study of hemodialysis patients from January 2021 to June 2021 who are routinely undergoing hemodialysis in Mogadishu Somali Turkish Training and Research Hospital.

The patients' age, sex, and diagnosis were extracted from the hospital database using Hospital Information System (HIS). Other variables such as duration of hemodialysis, number of hemodialysis sessions per week, and history of blood transfusion were collected from the patients through a multiple choice questionnaire. The questionnaire was taken by one of our authors to strength the accuracy of the data. Age, sex, duration of hemodialysis, number of hemodialysis sessions per week, history of blood transfusion, HbsAg, and anti-HCV antibodies were the examined variables.

In southern Somalia, there are only three hemodialysis centers which are located in the capital city of Mogadishu that serves hemodialysis patients. Mogadishu Somali Turkish Training and Research Hospital is the only tertiary hospital among these three hemodialysis centers and has served 300 hemodialysis patients through morning, noon, afternoon, and evening shifts.

The hospital has 30 hemodialysis machines, and 28 of them are used for non-HBV and non-HCV positive patients. One of the remaining two hemodialysis machines is used for $\mathrm{HBV}$ positive patients, and the other one is used for $\mathrm{HCV}$ positive patients. The hospital does not reuse the hemodialysis membrane, so every dialyzer is a one-time use. After every hemodialysis session, the hemodialysis machine is sterilized with 50\% citric acid liquid for 30 minutes before the next patient's session begins. Patients with HBV and $\mathrm{HCV}$ always take their hemodialysis sessions in separate rooms from non-HBV and non-HCV patients.

Most of the patients have one or two sessions of hemodialysis per week. This is due to the fact that the government is not covering the cost of hemodialysis patients, so every patient pays from his pocket. The other two hospitals have a total of 200 hemodialysis patients who are going to hemodialysis routinely.

Because of this, we used Raosoft website for determining the sample size. We assumed the total number of hemodialysis patients to be 500, and with 5\% margin of error and a confidence level of $95 \%$, a sample size of 220 patients was determined. Patients who were going to hemodialysis in less than 90 days and patients who were unwilling to participate were excluded from this study.

2.3. Laboratory Technique. $5 \mathrm{ml}$ of blood were drawn from every participant before the hemodialysis session. The samples were centrifuged for 5 minutes at a rate of $3000 \mathrm{rpm}$, and then serological qualitative tests for HbsAg and anti$\mathrm{HCV}$ antibodies were performed using enzyme-linked immunosorbent assay (ELISA) through a VITROS 3600 machine (Germany). The hospital did not have the capacity to test $\mathrm{HBV}$ and $\mathrm{HCV}$ genetic materials, and for that reason, we were unable to obtain that data.

2.4. Ethical Consideration. Informed consent was obtained from the patients. No personal data have been revealed in this study. The study had been evaluated and approved by the Mogadishu Somali Turkish Training and Research Hospital ethical committee.

2.5. Statistical Analysis. The data were collected and analyzed using Statistical Package for Social Sciences (SPSS) software version 26. Descriptive statistics, compare mean, Pearson correlations, and multiple regression were used in this study.

\section{Results}

Out of the 220 patients that were enrolled in the study, 113 (51.4\%) were males and 107 (48.6\%) were females. The mean age of the participants was 52.70 with maximum and minimum age ranging between 11 years and 88 years (Table 1). Among the 220 patients, 111 (50.4\%) have been undergoing hemodialysis between 12 months and 36 months. 
TABLE 1: The distribution of age and gender among respondents.

\begin{tabular}{lccc}
\hline & Age & & \\
Mean & & 52.70 & \\
Median & & 55.00 & \\
Std. deviation & & 18.479 & \\
Minimum & & 11 & \\
Maximum & & 88 & \\
& Gender & & Percentage \\
Male & Frequency & & $51.4 \%$ \\
Female & 113 & & $48.6 \%$ \\
Total & 107 & & $100 \%$ \\
\hline
\end{tabular}

$142(64.5 \%)$ of our respondents had 2 sessions of hemodialysis per week, $60(27.3 \%)$ respondents had once-aweek sessions, and 18 (8.2\%) had a frequency of 3 sessions of hemodialysis per week (Table 2).

In this study, the prevalence of $\mathrm{HBV}$ was $7.3 \%$ (16 respondents) and the prevalence of $\mathrm{HCV}$ was $3.2 \%$ (7 respondents). Only 1 respondent (0.5\%) is positive for both $\mathrm{HBV}$ and HCV (Table 3). The data also showed that, among the 16 respondents that were tested positive for HBV, twothirds of the respondents $(11(68.75 \%))$ were males while females comprised the remaining 5 respondents $(31.25 \%)$. Among the age subgroups, the prevalence of $\mathrm{HBV}$ was $0 \%$, $18.75 \%, 25 \%, 50 \%$, and $6.25 \%$ in less than 20 years, $21-40$ years, 41-60 years, 61-80 years, and more than 80 years, respectively. Of the 16 respondents who were $\mathrm{HBV}$ positive, $11(68.75 \%)$ had been on hemodialysis for more than 36 months while the remaining 5 respondents (31.25\%) have been on hemodialysis for 12-36 months. Out of the 7 respondents who were tested positive for $\mathrm{HCV}, 4$ respondents (57\%) were males and 3 respondents (43\%) were females. Among the age subgroups, the prevalence of HCV was $14.3 \%$, $0 \%, 28.6 \%, 57.1 \%$, and $0 \%$ in less than 20 years, $21-40$ years, 41-60 years, 61-80 years, and more than 80 years, respectively. Of the 7 respondents who were tested positive for $\mathrm{HCV}$, 5 (71.4\%) had more than 36 months of hemodialysis (Table 2). The majority of respondents (196 (89.1\%)) were seronegative for HBV and HCV (Table 3). The study found that there is a significant positive correlation between the duration of hemodialysis and the prevalence of HBV and HCV $(r(218)=$ $0.298, p$ value $<0.001)$. There is also a positive correlation between blood transfusion and the prevalence of $\mathrm{HBV}$ and HCV among hemodialysis patients $(r(218)=0.347, p$ value $<0.001)$. The study also found a highly significant positive correlation between the number of hemodialysis sessions per week and the prevalence of HBV and HCV $(r(218)=0.402, p$ value $<0.001$ ) (Table 4 ). The regression model of the combined predictors of history of blood transfusion, duration of dialysis, and the number of dialysis sessions per week is $R^{2}=0.25$, which indicates that they have a $25 \%$ variance in the prevalence of HBV and HCV among hemodialysis patients with a significance of $F(3,216)=23.67, p<0.001$ (Figure 1).

\section{Discussion}

Hepatitis B (HBV) and hepatitis $\mathrm{C}(\mathrm{HCV})$ are major causes of chronic liver inflammation and thus increase the morbidity and mortality of the patients [15]. Reduced immunity from chronic renal disease makes patients susceptible to succumb HBV and HCV infections [16]. Exposure to multiple blood transfusion and deficient immune response puts the patients with end-stage renal disease (ESRD) at increased risk of acquiring $\mathrm{HBV}$ and $\mathrm{HCV}$ infections than the general population [7].

A meta-analysis done by Hassan-Kadle et al. in 2018 found the prevalence of HBV infection in Somali population to be $18.9 \%$ with the $20-39$ age group having the highest prevalence of around $12.4 \%$. In addition, they also found the prevalence of HCV to be around $4.84 \%$ and $29.82 \%$ of them had already developed chronic liver disease [17].

Long-standing civil war, lack of centralized government, lack of laboratory techniques, and undertrained health workers contributed to the lack of data in many subgroup populations in Somalia [18].

In this study, we revealed the prevalence of $\mathrm{HBV}$ among hemodialysis patients to be $7.3 \%$ and the prevalence of $\mathrm{HCV}$ among hemodialysis patients to be $3.2 \%$. HBV was more common in males and in the age group of 61-80 years. Similarly, HCV was more common in males and in the age group of 61-80 years. We also found that there is a significant positive correlation between the prevalence of $\mathrm{HBV}$ and HCV and the history of blood transfusion, the duration of hemodialysis, and the number of hemodialysis sessions per week.

A study done by Almezgagi et al. about the prevalence of $\mathrm{HBV}$ and HCV and associated risk factors among hemodialysis patients in Ibb City, Yemen, in 2020 concluded that the prevalence of $\mathrm{HBV}$ is $3 \%, \mathrm{HCV}$ is $21 \%$, and coinfection $2 \%$ [19]. This conclusion is different from our study because we found that HBV was more common than HCV among hemodialysis patients in Somalia.

A similar study done in Khartoum, Sudan, by Gasim et al. in 2012 found HCV more common than HBV in $8.5 \%-$ $4.5 \%$, respectively. In contrast to our study, they also concluded that blood transfusion had no significant association with the prevalence of HBV and HCV [20].

A meta-analysis done by Ashkani-Esfahani et al. regarding the prevalence of hepatitis $\mathrm{C}$ virus infection among hemodialysis patients in the Middle East in 2017 reported $25.3 \%$ of the overall prevalence of $\mathrm{HCV}$ [21]. In contrast to that, we found that the prevalence of $\mathrm{HCV}$ is $3.2 \%$.

Furthermore, a meta-analysis of combined North Africa and Middle East done by Harfouche et al. about the prevalence of HCV among hemodialysis patients in 2017 had a result of $29.2 \%$ prevalence rate for $\mathrm{HCV}$ [22].

A study done in Lebanon by Rached et al. concluded that the prevalence of $\mathrm{HBV}$ and $\mathrm{HCV}$ is $1.6 \%$ and $4.7 \%$, respectively [23]. This also different from our conclusion that $\mathrm{HBV}$ was more common than $\mathrm{HCV}$ among hemodialysis patients in Somalia.

The higher prevalence of $\mathrm{HBV}$ than $\mathrm{HCV}$ in our study can be explained by the higher incidence of HBV among Somali population than HCV as reported by Hassan-Kadle et al. in 2018 [17].

Finally, this study intends to be the gateway of many researchers to look into this subject and for policy makers to 
TABLE 2: The prevalence of HBV and HCV in relation to demographic variables of the respondents.

\begin{tabular}{|c|c|c|c|c|c|c|}
\hline \multicolumn{2}{|c|}{ Demographic variables } & Negative & $\begin{array}{l}\text { Hepatitis } B \\
\text { positive }\end{array}$ & $\begin{array}{l}\text { Hepatitis } \mathrm{C} \\
\text { positive }\end{array}$ & $\begin{array}{l}\text { Both hepatitis } \mathrm{B} \text { and } \mathrm{C} \\
\text { positive }\end{array}$ & Total \\
\hline \multirow{6}{*}{ Age group } & $<20$ years & $13(6.6 \%)$ & $0(0 \%)$ & $1(14.3 \%)$ & $0(0 \%)$ & $14(6.4 \%)$ \\
\hline & $21-40$ years & $35(17.9 \%)$ & $3(18.75 \%)$ & $0(0 \%)$ & $0(0 \%)$ & $38(17.2 \%)$ \\
\hline & $41-60$ years & $72(36.7 \%)$ & $4(25 \%)$ & $2(28.6 \%)$ & $1(100 \%)$ & $79(36 \%)$ \\
\hline & $61-80$ years & $76(38.8 \%)$ & $8(50 \%)$ & $4(57.1 \%)$ & $0(0 \%)$ & $88(40 \%)$ \\
\hline & $>80$ years & $0(0 \%)$ & $1(6.25 \%)$ & $0(0 \%)$ & $0(0 \%)$ & $1(0.4 \%)$ \\
\hline & Total & $196(100 \%)$ & $16(100 \%)$ & $7(100 \%)$ & $1(100 \%)$ & $\begin{array}{c}220 \\
(100 \%)\end{array}$ \\
\hline \multirow{3}{*}{ Gender } & Male & $97(49.5 \%)$ & $11(68.7 \%)$ & $4(57 \%)$ & $1(100 \%)$ & $\begin{array}{c}113 \\
(51.4 \%)\end{array}$ \\
\hline & Female & $99(50.5)$ & $5(31.3 \%)$ & $3(43 \%)$ & $0(0 \%)$ & $\begin{array}{c}107 \\
(48.6 \%)\end{array}$ \\
\hline & Total & $196(100 \%)$ & $16(100 \%)$ & $7(100 \%)$ & $1(100 \%)$ & $\begin{array}{c}220 \\
(100 \%)\end{array}$ \\
\hline \multirow{4}{*}{ Duration of dialysis } & Less than 12 months & $52(26.5 \%)$ & $0(0 \%)$ & $1(14.3 \%)$ & $0(0 \%)$ & $53(24.1 \%)$ \\
\hline & $12-36$ months & $\begin{array}{c}105 \\
(53.5 \%)\end{array}$ & $5(31.25 \%)$ & $1(14.3 \%)$ & $0(0 \%)$ & $\begin{array}{c}111 \\
(50.4 \%)\end{array}$ \\
\hline & More than 36 months & $39(20 \%)$ & $11(68.75 \%)$ & $5(71.4 \%)$ & $1(100 \%)$ & $56(25.5 \%)$ \\
\hline & Total & $196(100 \%)$ & $16(100 \%)$ & $7(100 \%)$ & $1(100 \%)$ & $\begin{array}{c}220 \\
(100 \%)\end{array}$ \\
\hline \multirow{4}{*}{$\begin{array}{l}\text { No. of HD sessions/ } \\
\text { week }\end{array}$} & 1 session/week & $60(30.6 \%)$ & $0(0 \%)$ & $0(0 \%)$ & $0(0 \%)$ & $60(27.3 \%)$ \\
\hline & 2 sessions/week & $\begin{array}{c}131 \\
(66.8 \%)\end{array}$ & $6(37.5 \%)$ & $5(71 \%)$ & $0(0 \%)$ & $\begin{array}{c}142 \\
(64.5 \%)\end{array}$ \\
\hline & 3 sessions/week & $5(2.6 \%)$ & $10(62.5 \%)$ & $2(29 \%)$ & $1(100 \%)$ & $18(8.2 \%)$ \\
\hline & Total & $196(100 \%)$ & $16(100 \%)$ & $7(100 \%)$ & $1(100 \%)$ & $\begin{array}{c}220 \\
(100 \%)\end{array}$ \\
\hline \multirow{6}{*}{ Blood transfusion } & No blood transfusion & $\begin{array}{c}53 \\
(27.04 \%)\end{array}$ & $1(6.25 \%)$ & $2(28.6 \%)$ & $0(0 \%)$ & $56(25.5 \%)$ \\
\hline & $\begin{array}{l}\text { Less than } 5 \text { times } \\
\text { transfused }\end{array}$ & $83(42.3 \%)$ & $1(6.25 \%)$ & $1(14.3 \%)$ & $0(0 \%)$ & $85(38.6 \%)$ \\
\hline & 5-10 times transfused & $\begin{array}{c}42 \\
(21.42 \%)\end{array}$ & $6(37.5 \%)$ & $1(14.3 \%)$ & $0(0 \%)$ & $49(22.2 \%)$ \\
\hline & 10-15 times transfused & $17(8.7 \%)$ & $6(37.5 \%)$ & $1(14.3 \%)$ & $0(0 \%)$ & $24(11 \%)$ \\
\hline & $\begin{array}{c}\text { More than } 15 \text { times } \\
\text { transfused }\end{array}$ & $1(0.5 \%)$ & $2(12.5 \%)$ & $2(28.6 \%)$ & $1(100 \%)$ & $6(2.7 \%)$ \\
\hline & Total & $196(100 \%)$ & $16(100 \%)$ & $7(100 \%)$ & $1(100 \%)$ & $\begin{array}{c}220 \\
(100 \%)\end{array}$ \\
\hline
\end{tabular}

TABLE 3: The prevalence of HBV and HCV among hemodialysis patients in Somalia.

\begin{tabular}{lcc}
\hline Serological results & Frequency & Percent \\
\hline Negative & 196 & 89.1 \\
Hepatitis B positive & 16 & 7.3 \\
Hepatitis C positive & 7 & 3.2 \\
Both hepatitis B and C positive & 1 & 0.5 \\
Total & 220 & 100.0 \\
\hline
\end{tabular}

TABLE 4: The correlations between the prevalence of HBV and HCV and the number of hemodialysis sessions/week, blood transfusion, and duration of dialysis.

\begin{tabular}{lcc}
\hline & Prevalence of HBV and HCV & \\
\hline & Pearson correlation & $0.402^{* *}$ \\
No. of HD sessions per week & Sig. (2-tailed) & 0.000 \\
& $N$ & 220 \\
& Pearson correlation & $0.347^{* *}$ \\
Blood transfusion & Sig. (2-tailed) & 0.000 \\
& $N$ & 220 \\
Duration of dialysis & Pearson correlation & $0.298^{* *}$ \\
& Sig. (2-tailed) & 0.000 \\
\end{tabular}

\footnotetext{
${ }^{* *}$ means there is a correlation between the variables.
} 


\begin{tabular}{|c|c|c|c|c|}
\hline \multirow[b]{2}{*}{ Model } & \multicolumn{3}{|c|}{ Regression Model Summary } & \multirow[b]{2}{*}{$\begin{array}{l}\text { Std. Error of the } \\
\text { Estimate }\end{array}$} \\
\hline & $\mathrm{R}$ & R Square & $\begin{array}{l}\text { Adjusted R } \\
\text { Square }\end{array}$ & \\
\hline 1 & $.497^{\mathrm{a}}$ & .247 & .237 & .4092 \\
\hline
\end{tabular}

\begin{tabular}{|c|c|c|c|c|c|c|}
\hline \multicolumn{7}{|c|}{ ANOVA $^{\mathrm{a}}$} \\
\hline Model & & Sum of Squares & $\mathrm{df}$ & Mean Square & $\mathrm{F}$ & Sig. \\
\hline \multirow[t]{3}{*}{1} & Regression & 11.890 & 3 & \multirow{3}{*}{$\begin{array}{r}3.963 \\
.167\end{array}$} & \multirow[t]{3}{*}{23.674} & \multirow[t]{3}{*}{$.000^{\mathrm{b}}$} \\
\hline & Residual & 36.160 & 216 & & & \\
\hline & Total & 48.050 & 219 & & & \\
\hline
\end{tabular}

FIGURE 1: The regression model and its significance of the predictors towards the prevalence of HBV and HCV among hemodialysis patients.

implement good public health strategies to tackle this growing public health issue.

One of our study limitations is the absence of data of $\mathrm{HBV}$ and HCV testing at the molecular level because there may be cases of hidden HBV that could not be detected through the ELISA test. The other limitation is that there is no specific number of the prevalence of hemodialysis patients in Somalia. This is due to lack of previous study publication regarding this subject.

\section{Conclusion}

The prevalence of HBV and HCV among hemodialysis patients in this study was $7.3 \%$ and $3.2 \%$, respectively. $0.5 \%$ of the respondents had both $\mathrm{HBV}$ and $\mathrm{HCV}$. History of blood transfusion, duration of hemodialysis, and number of hemodialysis sessions per week appear to have a strong correlation with the prevalence of HBV and HCV. Implementation of good infectious control plans, patient education, immunizing patients against $\mathrm{HBV}$, and minimizing the patients' need of blood transfusion by close follow-up can be taken to lower the chance of getting HBV and HCV infections. Upon working on this study, the authors clearly saw firsthand the need to know the prevalence of hemodialysis patients in Somalia, so we also urge other researchers to immediately focus on that subject. The study only focused on a single tertiary hospital in Somalia, so a nation-wide study is needed to determine the prevalence of $\mathrm{HBV}$ and $\mathrm{HCV}$ among this group of population in Somalia.

\section{Abbreviations}

$\begin{array}{ll}\text { Anti-HCV: } & \text { Anti-hepatitis C virus antibody } \\ \text { ELISA: } & \text { Enzyme-linked immunosorbent assay } \\ \text { HBV: } & \text { Hepatitis B virus } \\ \text { HCV: } & \text { Hepatitis C virus } \\ \text { HbsAg: } & \text { Hepatitis B surface antigen } \\ \text { Ml: } & \text { Milliliter } \\ \text { RPM: } & \text { Round per minute }\end{array}$

WHO: World Health Organization

SPSS: $\quad$ Statistical package for social sciences.

\section{Data Availability}

The data are available from the corresponding author upon request.

\section{Conflicts of Interest}

The authors declare that they have no conflicts of interest.

\section{Authors' Contributions}

Mohamed OOJ brought the idea of the research, performed data collection and data analysis, and prepared the manuscript. Rukia OBA participated in the data collection and data analysis. Faduma NA handled the laboratory samples and participated in the data analysis. Liban $\mathrm{HJ}$ participated in the data analysis and manuscript preparation. All authors read and approved the manuscript before submitting.

\section{Acknowledgments}

The authors thank all patients who gave their consent to be involved in this study.

\section{References}

[1] S. L. James, D. Abate, K. H. Abate et al., "Global, regional, and national incidence, prevalence, and years lived with disability for 354 diseases and injuries for 195 countries and territories, 1990-2017: a systematic analysis for the global burden of disease study 2017," The Lancet, vol. 392, no. 10159, pp. 1789-1858, 2018.

[2] "Hepatitis B," 2020, https://www.who.int/.

[3] M. Schwalbe, O. Ohlenschläger, A. Marchanka et al., "Solution structure of stem-loop $\alpha$ of the hepatitis B virus posttranscriptional regulatory element," Nucleic acids research, vol. 36, no. 5, pp. 1681-1689, 2008. 
[4] World Health Organisation, Global Hepatitis Report 2017 (Report), World Health Organisation, Geneva, Switzerland, 2017.

[5] A. Maheshwari and P. J. Thuluvath, "Management of acute hepatitis C," Clinics in Liver Disease, vol. 14, no. 1, pp. 169-176, 2010.

[6] Q\&A for Health Professionals, Viral Hepatitis, Centers for Disease Control and Prevention, Atlanta, GA, USA, 2020.

[7] T. Adane and S. Getawa, "The prevalence and associated factors of hepatitis $\mathrm{B}$ and $\mathrm{C}$ virus in hemodialysis patients in Africa: a systematic review and meta-analysis," PLoS One, vol. 16, no. 6, Article ID e0251570, 2021.

[8] W. A. Alashek, C. W. McIntyre, and M. W. Taal, "Hepatitis B and $\mathrm{C}$ infection in haemodialysis patients in Libya: prevalence, incidence and risk factors," BMC Infectious Diseases, vol. 12, no. 1, pp. 265-268, 2012.

[9] A. R. Nissenson and R. E. Fine, Handbook of Dialysis Therapy, Elsevier Health Sciences, Amsterdam, Netherlands, 2016.

[10] H. S. Choi, K. D. Han, T. R. Oh et al., "Trends in the incidence and prevalence of end-stage renal disease with hemodialysis in entire Korean population: a nationwide population-based study," Medicine, vol. 100, no. 13, 2021.

[11] A. Gaipov, A. Issanov, K. Kadyrzhanuly et al., "Epidemiology of dialysis-treated end-stage renal disease patients in Kazakhstan: data from nationwide large-scale registry 2014-2018," BMC Nephrology, vol. 21, no. 1, pp. 1-9, 2020.

[12] G. Wong, K. Howard, J. R. Chapman et al., "Comparative survival and economic benefits of deceased donor kidney transplantation and dialysis in people with varying ages and co-morbidities," PLoS One, vol. 7, no. 1, Article ID e29591, 2012.

[13] J. G. Gonzalez-Perez, L. Vale, S. C. Stearns, and S. Wordsworth, "Hemodialysis for end-stage renal disease: a cost-effectiveness analysis of treatment options," International Journal of Technology Assessment in Health Care, vol. 21, no. 1, pp. 32-39, 2005.

[14] A. D. Kaze, T. Ilori, B. G. Jaar, and J. B. Echouffo-Tcheugui, "Burden of chronic kidney disease on the African continent: a systematic review and meta-analysis," BMC Nephrology, vol. 19, no. 1, p. 125, 2018.

[15] V. Kumar, S. Das, and S. Jameel, "The biology and pathogenesis of hepatitis viruses," Current Science, vol. 98, pp. 312-325, 2010.

[16] S. Pol, A. Vallet-Pichard, M. Corouge, and V. O. Mallet, "Hepatitis C: epidemiology, diagnosis, natural history and therapy," Hepatitis C in Renal Disease, Hemodialysis and Transplantation, vol. 176, pp. 1-9, 2012.

[17] M. A. Hassan-Kadle, M. S. Osman, and P. P. Ogurtsov, "Epidemiology of viral hepatitis in Somalia: systematic review and meta-analysis study," World Journal of Gastroenterology, vol. 24, no. 34, pp. 3927-3957, 2018.

[18] M. A. Hassan-Kadle and A. Mohamed, "The diagnostic challenges, possible etiologies and lack of researches of hepatocellular carcinoma in Somalia," Open Journal of Gastroenterology, vol. 7, no. 3, p. 115, 2017.

[19] M. M. Almezgagi, W. H. Edrees, W. A. Al-Shehari, K. AlMoyed, R. S. Al-Khwlany, and A. B. Abbas, "Prevalence of hepatitis $\mathrm{B}$ virus and hepatitis $\mathrm{C}$ virus and associated risk factors among hemodialysis patients in Ibb city-Yemen," PSM Microbiology, vol. 5, no. 2, pp. 32-40, 2020.

[20] G. I. Gasim, H. Z. Hamdan, S. Z. Hamdan, and I. Adam, "Epidemiology of hepatitis B and hepatitis $\mathrm{C}$ virus infections among hemodialysis patients in Khartoum, Sudan," Journal of Medical Virology, vol. 84, no. 1, pp. 52-55, 2012.
[21] S. Ashkani-Esfahani, S. M. Alavian, and M. Salehi-Marzijarani, "Prevalence of hepatitis $C$ virus infection among hemodialysis patients in the Middle-East: a systematic review and meta-analysis," World Journal of Gastroenterology, vol. 23, no. 1, p. 151, 2017.

[22] M. Harfouche, H. Chemaitelly, S. Mahmud et al., "Epidemiology of hepatitis $\mathrm{C}$ virus among hemodialysis patients in the Middle East and North Africa: systematic syntheses, metaanalyses, and meta-regressions," Epidemiology and Infection, vol. 145, no. 15, pp. 3243-3263, 2017.

[23] A. A. Rached, L. E. Khoury, T. E. Imad, A. S. Geara, J. Jreijiry, and W. Ammar, "Incidence and prevalence of hepatitis B and hepatitis C viruses in hemodialysis patients in Lebanon," World Journal of Nephrology, vol. 5, no. 1, p. 101, 2016. 